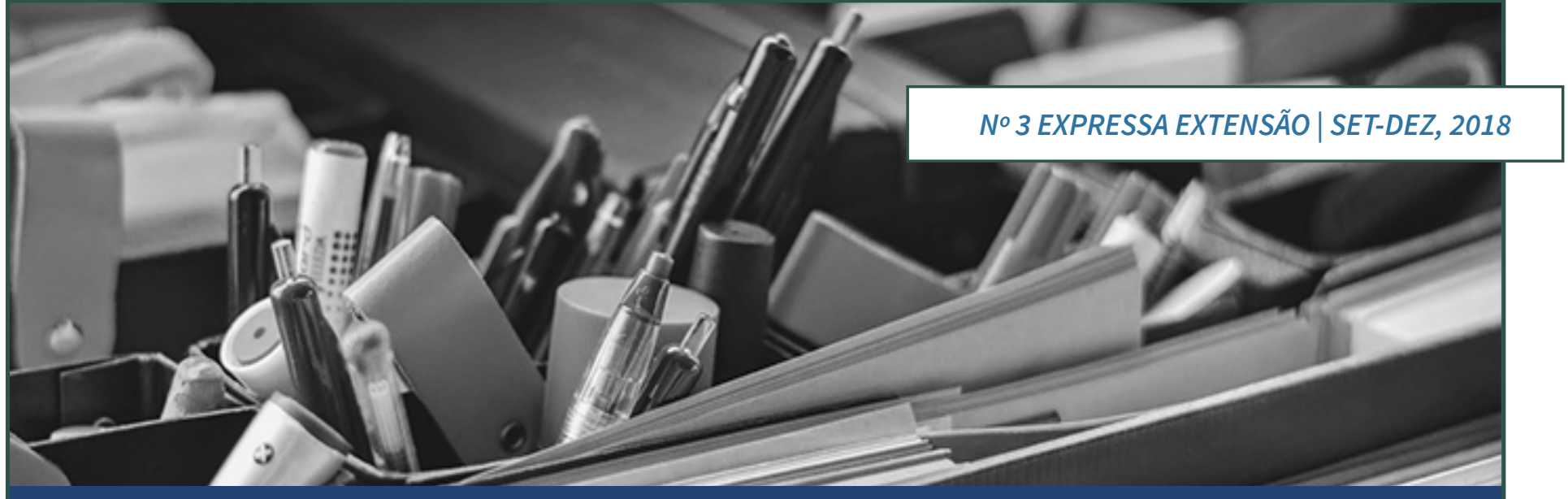

\title{
PROPOSTA EXTENSIONISTA SOBRE INCLUSÃO ESCOLAR: DA EDUCAÇÃO BÁSICA AO SUPERIOR
}

EXTENSION PROPOSAL ON SCHOOL INCLUSION: FROM BASIC TO HIGHER EDUCATION

\section{Priscila Benitez ${ }^{1} \quad$ Elisabete Marcon Mello²}

Hadassa Rodrigues Santos ${ }^{3}$ Rogério Timóteo Tiné ${ }^{4}$

\section{RESUMO}

O objetivo desse trabalho foi descrever e operacionalizar a organização de uma ação extensionista sobre educação especial e inclusiva, cuja demanda emergiu a partir do diálogo com a comunidade escolar, bem como das lacunas identificadas e literatura acerca de formação continuada e permanente de professores para atuação em uma perspectiva inclusiva, por meio do arcabouço teórico reflexivo. A ação extensionista, por meio de um evento que ocorreu em dois períodos, visou um primeiro momento com a discussão de conceitos teóricos, em uma mesa-redonda e, no outro período apresentação de práticas pedagógicas dos universitários que cursaram a disciplina de Educação Inclusiva, assim como dos professores da rede municipal e estadual de ensino. O procedimento metodológico foi organizado em três etapas, envolvendo a caracterização da realidade educacional do município-alvo em relação à inclusão, para posteriormente definir a ação extensionista e, por último, analisar os resultados obtidos com a ação. Os resultados foram discutidos em relação às principais características dos participantes inscritos, temas discutidos no momento da mesa-redonda e temas discutidos no momento das apresentações de trabalhos.Espera-se que o evento tenha contribuído com a disseminação de práticas inclusivas no âmbito da educação básica ao superior, por meio do envolvimento de professores da rede municipal e estadual, comunidade interna e externa da universidade.

Palavras-chave: Educação especial. Educação inclusiva. Ação extensionistas.

\footnotetext{
${ }^{1}$ Universidade Federal do ABC - Brasil - Professora Doutora em Psicologia - priscila.benitez@ufabc.edu.br; ${ }^{2}$ Universidade Federal do ABC - Brasil - Professora Doutora em Educação Matemática - marcon.elisabete@gmail.com; ${ }^{3}$ Universidade Federal do ABC - Brasil - Doutoranda em Linguística e Língua Portuguesa. Mestra em Linguística e Língua Portuguesa. Tradutora e Intérprete de Libras-Português - hadassa.santos@ufabc.edu.br; ${ }^{4}$ Universidade Federal do ABC - Brasil - Mestre na área de Linguística, com ênfase em Linguística Aplicada e Estudos da Linguagem. Especialista em Libras e Educação de Surdos - rogerio.timoteo@ufabc.edu.br
} 


\section{ABSTRACT}

The aim of this work was to describe and operationalize the organization of an extension action on special and inclusive education, whose demand emerged from the dialogue with the school community, as well as from the identified literature gaps about continuing and permanent teacher training for action in an inclusive perspective, through the reflective theoretical framework. The extension's action, through an event that occurred in two periods, aimed at a first moment with the discussion of theoretical concepts, in a round table and, in the other period, the presentation of pedagogical practices of the students who attended the Inclusive Education course, as well as teachers from the municipal and state education network. The methodological procedure was organized in three stages, involving the characterization of the educational reality of the target municipality in relation to inclusion, to later define the extension's action and, finally, to analyze the results obtained with the action.The results were discussed in relation to the main characteristics of the enrolled participants, topics discussed at the time of the roundtable and topics discussed at the time of the presentations. It is hoped that the event contributed to the dissemination of inclusive practices in basic to higher education, through the involvement of teachers from the municipal and state network, the university's internal and external community.

Keywords: Special education. Inclusive education. Extension's action.

\section{INTRODUÇÃO}

De acordo com aPolítica Nacional de Educação Especial na Perspectiva da Educação Inclusiva (BRASIL, 2008), o movimento mundial pela educação inclusiva é uma ação política, cultural, social e pedagógica, desencadeada em defesa do direito de todos os alunos estarem juntos, aprendendo e participando, sem nenhum tipo de discriminação. Essa Política estabelece que os sistemas de ensino devem organizar as condições de acesso aos espaços, aos recursos pedagógicos e à comunicação que favoreçam a promoção da aprendizagem e a valorização das diferenças, de forma a atender as necessidades educacionais de todos os alunos, perpassando desde à educação básica até o superior, devido a transversalidade do ensino.

O Censo Demográfico de 2010, divulgado pelo Instituto Brasileiro de Geografia e Estatística (IBGE), mostra que mais de 45,6 milhões de brasileiros declaram ter alguma deficiência. Os dados do Censo Escolar (BRASIL, 2015) indicam que no ano de 2014, de um total de quase 900 mil estudantes especiais, 698.768 estavam matriculados em classes comuns, o que, de acordo com o documento, representa um crescimento expressivo em relação às matrículas de alunos com deficiência na educação básica regular, pois, em 1998, cerca de 200 mil pessoas estavam matriculadas na educação básica, mas apenas $13 \%$ delas estavam em classes comuns. 
Para garantir a educação de qualidade para todos os alunos, independentemente de suas condições físicas, intelectuais, sociais e emocionais, além de infraestrutura e condições materiais, são necessários profissionais qualificados, capazes de enxergar as potencialidades desses alunos e criar estratégias para que todos eles sejam expostos a um ensino de qualidade. Segundo Gatti e Barretto(2009), poucos cursos de licenciatura em Pedagogia propõem disciplinas que permitam algum aprofundamento e formação de competências na área de educação infantil, e menos ainda em relação a modalidades educacionais como educação especial. Dessa forma, muitos professores que atuam em salas de aula inclusivas, o fazem sem formação adequada, o que desencadeia dúvidas e insegurança em relação ao seu próprio trabalho.

O estudo de Rodrigues, Moreira e Lerner (2012) identificou lacunas sobre as questões institucionais relacionadas à inclusão de alunos com autismo, especialmente no que concerne ao trabalho do professor em sala de aula. Estes, por sua vez, apresentam muitas vezes práticas relacionadas apenas às atividades de vida diária, com olhar comparativo aos alunos sem deficiência/transtorno e caracterizam esse público como uma demanda desafiadora para aplicar as atividades pedagógicas na sala de aula (RODRIGUES; MOREIRA; LERNER, 2012).

Os dados de Silveira e Neves (2006) corroboram as mesmas dificuldades levantadas por Rodrigues, Moreira e Lerner (2012), em relação aos desafios sobre a inclusão escolar de alunos com deficiência múltipla. Os autores entrevistaram pais e professores e realizaram observações no contexto escolar. Os resultados reportaram que tanto os pais, como os professores não acreditam na inclusão escolar desse público-alvo, devido à falta de organização escolar para trabalhar com tais alunos e ausências de formações continuadas para os professores.

Uma queixa, comumente apresentada por diferentes professores, é sobre a presença de capacitações teóricas, que discutem apenas diretrizes políticas e normativas e não contemplam o desenvolvimento de atividades e que os orientem sobre como trabalhar com os estudantes. As queixas, relatadas por eles, envolvem desde a dificuldade para desenvolver atividades pedagógicas com esse alunado, a ausência de conhecimentos e formação, até a ausência de preparo para lidar com os problemas de comportamentos (MENDES; ALMEIDA; TOYODA, 2011; SILVIERA; NEVES, 2006).

Tais constatações evidenciam a necessidade de momentos que permitam que esses profissionais compartilhem suas experiências e discutam suas práticas, possibilitando a disseminação de atitudes positivas e a correção de práticas equivocadas. Visando suprir, ainda que de maneira incipiente, a lacuna de formação do professor, além de criar um espaço de encontro e reflexão para profissionais que trabalham com a educação inclusiva, desde à educação básica ao superior, foi realizado, em dezembro de 2017, o I Encontro de Educação Especial e Inclusiva da Universidade Federal do $A B C$ (UFABC), que fomentou discussões a 
respeito do processo de inclusão e possibilitou que professores de escolas públicas, que trabalham em salas de aula inclusivas, compartilhassem suas experiências e práticas docentes, assim como os alunos de graduação, em formação inicial, pudessem apresentar as práticas desenvolvidas no âmbito da disciplina de Educação Inclusiva. O evento foi elaborado e implantado de acordo com a perspectiva reflexiva discutida por Schon (2000). É na reflexão sobre a ação que é possivel tomar consciência do conhecimento tácito e reformular o pensamento na ação tentando analisá-la, percebendo que é um ato natural. A reflexão sobre a reflexão na ação é aquela que ajuda o profissional a se desenvolver e construir sua forma pessoal de conhecer. Trata-se de olhar retrospectivamente a ação, refletir sobre o momento da reflexão na ação: o que aconteceu, o que se observou, qual o significado atribuído e que outros significados podemos atribuir ao que aconteceu (SCHÖN, 2000 apud TINE, 2015, p.30).

A distinção do processo de reflexão-na-ação acontece em cinco momentos, de acordo com Schön (2000, p. 33-4 apud TINE, 2015, p.32), a destacar:1) respostas espontâneas e rotineiras: processo de conhecer-na-ação, em que as estratégias, compreensão e maneiras de apresentação de tarefas adequadas às situações do cotidiano e os resultados são obtidos de forma satisfatória, por efeito do conhecimento tácito ora já adquirido; 2 ) respostas de rotina produzem uma surpresa: um resultado inesperado é percebido, agradável ou desagradável, que não se adequa às categorias do conhecer-na-ação; 3 ) a surpresa leva à reflexão: o fator surpresa faz que conscientemente seja possível pensar sobre o conhecer-na-ação, mesmo que não haja a verbalização da reflexão; 4) a reflexão-na-ação tem função crítica: mais do que pensar na ação, a reflexão impulsiona a rever estratégias da ação, compreensão das situações e outras formas de expor e conceber problemas; 5) a reflexão gera experimento imediato: refletir direciona experimentos de novas ações, objetivando novas compreensões.

A implementação do evento, pautada na perspectiva reflexiva (SCHON, 2000; TINÉ, 2015) dialoga com o tripé ensino-pesquisa-extensão, proposto no âmbito da universidade pública. Assim, a ação extensionista proposta no presente estudoobjetivou garantirações que suprimissem a lacuna de formação, de modo a articular com os diferentes segmentos sociais, apoiados em uma Pró-Reitoria de Extensão e Cultura (ProEC), responsável por desenvolver ações extensionistas na UFABC. Uma das atribuições inerentes às universidades públicas brasileiras é atender às necessidades do país e de sua população. Distribuídas por todo o território nacional, em toda a sua existência sempre estiveram associadas ao desenvolvimento econômico, social, cultural e político da nação.De tal modo, a par de constituírem-se em espaços privilegiados para a produção, a acumulação e a disseminação de conhecimentos, as Instituições de Ensino Superior (IES) possuem um enorme potencial para a elaboração de políticas públicas, que tenham a cidadania e o cidadão como as suas principais referências na solução dos problemas nacionais.Para que isso ocorra, as IES, por meio das Pró-reitorias de Extensão ou órgãos equivalentes, devem atuar na democratização do conheci- 
mento e, ao mesmo tempo, respeitar e utilizar os diversos saberes na construção do conhecimento a ser desenvolvido, levando-se em conta as especificidades e demandas de cada comunidade em que atuam.

Com isso, espera-se a criação valorização de programas e ações de extensão ou de programas interinstitucionais, realizados sob a forma de consórcios, redes ou parcerias com secretarias dos governos federal, estaduais, municipais ou ONGs. Além da sua importância como geradora de políticas públicas, os órgãos de Extensão Universitária devem servir como instrumento de inclusão social, aproximando a academia das comunidades adjacentes.É nesse contexto que a ProEC da UFABC tem por missão promover a interação transformadora entre a UFABC e outros setores da sociedade, por meio de um processo educativo, cultural, científico e político, impactando diretamente na formação discente.As ações de extensão na ProEC acontecem sob a forma de programa, cursos, projetos e oficinas, numa forma bidirecional - universidade/sociedade/universidade e consideram a indissociabilidade entre a tríade ensino,pesquisa e extensão.Em uma resolução interna elaborada no ano de 2016, a UFABC define as atividades de Extensão Universitária. Em seu artigo $1^{\circ}$ preconiza que essas atividades devem promover de maneira direta a interação transformadora entre Universidade e sociedade, por meio de processos interdisciplinares, educativos, culturais, científicos e/ou políticos, sob o princípio constitucional da indissociabilidade entre a própria extensão, o ensino e a pesquisa.A fim de esclarecer o que considera como interação transformadora, o parágrafo 1salienta: "Entende-se por interação transformadora aquela que visa a alteração da percepção do indivíduo ou comunidade com relação ao seu estágio anterior" (RESOLUÇÃO DO CEU Nº 005, DE 11 DE JULHO DE 2016).Desta forma, a realização do I Encontro de Educação Especial e Inclusiva da UFABC veio fortalecer essas ações transformadoras ao dar acesso à comunidade externa ao debate e construção de políticas públicas que favoreçam o ingresso e permanência no ambiente acadêmico do público-alvo da educação especial e inclusiva, envolvendo desde práticas da educação básica ao superior, devido a transversalidade da educação especial.

Assim sendo, o objetivo desse trabalho foi descrever e operacionalizar a organização de uma ação extensionista sobre educação especial e inclusiva, cuja demanda emergiu a partir do diálogo com a comunidade escolar de uma cidade do interior do estado de São Paulo, em diálogo com os achados resgatados na literatura. Os dados discutidos ao longo do presente trabalho favoreceram a discussão e o aperfeiçoamento na relação ensino-aprendizagem dos profissionais da área educação especial e inclusiva e dos graduandos que cursaram a disciplina Educação Inclusiva da UFABC, bem como fomentaram a participação dos pais e comunidade externa interessada na temática.Para que os objetivos pudessem ser alcançados, as reflexões foram consideradas como parte fundamental da apropriação de novos saberes, por meio dos pressupostos teóricos embasados em Schön (2000), por se referiremaos principais conceitos de reflexão necessários à construção de novos conceitos e práticas pedagógicas voltadas ao público-alvo da educação especial e inclusiva. 


\section{MÉTODO}

A ação extensionista ocorreu em três etapas, descritas a seguir.

\section{Etapa 1: caracterizar a realidade educacional do município-alvo em relação à inclusão}

O primeiro passo para o desenvolvimento da ação extensionista foi entrar em contato com a Secretaria Municipal de Educação do município em que tal ação foi implantada, assim como com as escolas estaduais, visando compreender junto aos gestores como ocorria o processo inclusivo do público-alvo da educação especial. Foram conduzidas reuniões e trocas de informações, com o propósito de levantar as demandas reais e atuais tanto das escolas municipais, como das escolas estaduais. Os resultados dessas reuniōes versaram na identificação das seguintes lacunas: a) dificuldades para obtenção de recursos para implementação efetiva do processo inclusivo, de modo a atender todos os alunos; b) garantir tecnologia assistiva para todos os alunos que carecem de tal recurso; c) formação permanente dos professores e cuidadores/estagiários.

Para uma primeira ação conjunta entre universidade e os gestores das escolas municipais e estaduais tais lacunas foram elencadas em uma ordem de prioridade pela comunidade, de modo que a formação permanente dos professores e cuidadores/estagiários foi aquela considerada como prioritária por todos os gestores envolvidos.

\section{Etapa 2: Definição da ação extensionista (tema, público-alvo, duração, organi- zação geral)}

Após as reuniōes realizadas na etapa anterior, foram definidos três objetivos, são eles: a) um de curto prazo (elaboração de um evento gratuito), de modo a criar condições para fomentar a discussão sobre educação especial e inclusiva de uma maneira mais urgente;b) um objetivo intermediário (elaboração de um curso de extensão gratuito) e; c) outro objetivo de longo prazo (criação de uma especialização gratuita). O presente estudo limitou-se ao cumprimento do primeiro objetivo de curto prazo.

Como a proposta extensionista visa a articulação com o ensino, o evento propôs-se a estabelecer um diálogo entre a formação inicial e continuada de todos os professores, resultando, portanto, em uma formação permanente, perpassando desde a educação básica ao superior. Dessa forma, o evento foi organizado em dois períodos, com dois propósitos complementares. O primeiro visou fomentar a discussão teórica, acerca do tema "Educação Especial e Inclusiva", a partir da composição de uma mesa-redonda composta por um professor da UFABC, um professor doutor externo à universidade, um técnico-administrativo da UFABC, chefe responsável pelo Núcleo de Acessibilidade da universidade, dois gestores 
da educação especial na educação básica e um professor da rede municipal. 0 segundo período visou disseminar as práticas pedagógicas desenvolvidas pelos professores em formação inicial (universitários da UFABC que cursaram a disciplina de Educação Inclusiva) e professores em formação continuada e permanente da rede municipal e estadual. A proposta visou intercalar a apresentação de uma prática pedagógica desenhada pelos universitários, ao longo da disciplina de Educação Inclusiva, com a apresentação de uma prática desenvolvida e implementada pelos professores da rede municipal e estadual, envolvendo o público-alvo da educação especial.

Devido ao número elevado de inscrições para apresentações de trabalho $(n=52)$, o segundo momento do evento ocorreu em quatro salas distintas da UFABC e contou com a participação de quatro debatedores para fomentar a discussão dos dados apresentados pelos inscritos. De maneira geral, o evento foi aberto a toda comunidade, por meio de divulgação entre a rede municipal e estadual de ensino, assim como pela própria universidade e veículos de comunicação online, por exemplo, Facebook. O evento garantiu a acessibilidade para todos os inscritos, com a tradução e interpretação simultânea para a Língua Brasileira de Sinais (Libras), acompanhantes para mobilidade e descrições orais sobre os conteúdos expostos nos slides.

\section{Etapa 3: Análise dos resultados obtidos com a ação extensionistas}

A análise do evento foi pautada no número de inscrições para participação do evento, apresentações dos trabalhos, levantamento de questões/dúvidas ao longo do evento.

\section{RESULTADOS E DISCUSSÃO}

O objetivo do estudo foi descrever e operacionalizar a organização de uma ação extensionista sobre educação especial e inclusiva, cuja demanda emergiu a partir do diálogo com a comunidade escolar de uma cidade do interior do estado de São Paulo, em diálogo com os achados resgatados na literatura. A ação extensionista descrita visou o cumprimento de um objetivo de curto prazo, delineado junto aos gestores municipais e estaduais da educação básica. Os dados foram analisados de acordo com os seguintes eixos de análise: a) principais características dos inscritos, em relação ao município em que residem/trabalham e área de atuação; b) temas discutidos no momento da mesa-redonda; c) temas discutidos no momento das apresentações de trabalhos.

Em uma análise geral, sobre a demanda de pessoas interessadas na temática sobre a educação especial e inclusiva, o evento contou com 440 inscrições, sendo que desse total, participaram 316 pessoas do evento, envolvendo professores da rede municipal de diferentes cidades (São Paulo, Santo André, 
São Bernardo do Campo, Mauá, Ribeirão Pires, São Caetano, Barueri, Suzano, Diadema, Mogi das Cruzes, Itaquaquecetuba, Guarulhos, Francisco da Rocha, Francisco Morato, Vitória-ES, Rio Claro, São Roque, Jundiai, Carapicuíba, Osasco, Arujam).Os profissionais envolvidos apresentaram formações distintas, desde professores da rede pública e privada de educação infantil, ensino fundamental e médio, educação superior pública e privada, psicólogos, psicopedagogos, neuropsicopedagogos, fonoaudiólogos, técnicos educacionais, assistentes pedagógicos, diretores, coordenadores, tradutores e intérpretes de Libras, contador, pais, familiares, engenheiro aeronáutico, universitários de diversas áreas, estagiários/ cuidadores, vigilante, biólogo, diácono, advogado. A procura pelo evento por diferentes profissionais residentes em cidades distintas justifica o desenvolvimento de eventos futuros sobre a temática proposta a respeito da educação especial e inclusiva.

No tocante ao primeiro momento do evento, foi proposta uma discussão acerca do contexto histórico e normativo da educação inclusiva, assim como sobre as práticas inclusivas para estudantes surdos, perpassando desde a educação básica ao superior, estratégias municipais acerca da inclusão na educação básica, estratégias da UFABC e práticas do Núcleo de Acessibilidade sobre a inclusão na educação superior e por último, foram elencados os desafios e as possibilidades futuras da educação inclusiva brasileira. Após a exposição de cada tema foi realizada uma rodada de perguntas, em torno de uma hora, cujos temas recorrentes do debate envolveram: a) inclusão do estudante surdo e práticas pedagógicas, alfabetização e formação de profissionais em Libras; b) práticas da UFABC para garantir a inclusão na educação superior, visando a formação dos docentes da universidade de áreas que não envolvem as licenciaturas, como os bacharelados em ciências exatas; c) avaliação na educação básica e no superior, dentre outros. Em relação ao segundo momento do evento, as apresentações $(n=54)$ foram agrupadas, de acordo com as possibilidades, envolvendo o público-alvo da educação especial. Os temas disparadores envolveram: a) deficiência visual, cego, surdo, tecnologia assistiva, comunicação alternativa, atendimento domiciliar, hospitalar, conteúdos acadêmicos; b) transtorno do espectro do autismo, deficiência física, paralisia cerebral, educação física, natação; c) altas habilidades/ superdotação, EJA, sala de recurso multifuncional, síndrome de Down, deficiência intelectual; d) parceria inclusiva, práticas pedagógicas, creche, ensino fundamental.Assim, o evento garantiu a participação de universitários da UFABC que cursaram a disciplina de Educação Inclusiva (profissionais em formação inicial), em conjunto, com os professores que atuavam na rede municipal e estadual (profissionais em formação continuada e permanente).

A proposição da ação extensionista, por meio de um evento, visou de maneira ainda que embrionária, atender as lacunas identificadas na literatura em estudos anteriores (GATTI; BARRETO, 2009; MENDE et al., 2011; RODRIGUES et al., 2012; SILVEIRA; NEVES, 2006), acerca da formação permanente de profissionais envolvidos com o processo inclusivo da educação especial, de acordo com as normativas legais (BRASIL, 2008). 
Ademais, a apresentação dos trabalhos pelos universitários, assim como pelos professores propiciou momentos de reflexão sobre as práticas pedagógicas. Refletir sobre a ação, examinando retrospectivamente o que aconteceu e tentando descobrir como a ação pode ter contribuído para o resultado, é uma forma de garantir reflexões acerca das práticas pedagógicas apresentadas pelos professores. Outra forma de oportunizara tais reflexões pode ser por meio do refletir no meio da ação, sem interrompê-la, chamando esse processo de reflexão-na-ação; nesse momento, o pensar pode dar uma nova forma ao que está sendo realizado, o que significar refletir-na-ação (SCHON, 2000).

Quando Schön inicia a percepção das práticas profissionais, a conversa reflexiva que acontece com a parceria de outros participantes é o centro da reflexão sobre a prática. As atividades propostas aos universitários, além das conversas reflexivas com professores e profissionais da área da educação especial e inclusiva, cooperaram, ainda que de maneira incipiente, nas construções de sentidos-e-significados, na melhoria da compreensão e na configuração de novos conhecimentos e experiências, tanto individuais quanto em parceria. Nesse sentido, Schön (2000, p. 226 apud TINE, 2015, p.30) impele a refletir como um "ensino prático reflexivo" poderia produzir mudanças e quais implicações ocorreriam numa atividade prática social. Schön (2000, p. 227 apud TINE, 2015, p.30) também mostra que, para evitar que a prática se torne isolada, "[...] devemos cultivar atividades que conectem o conhecimento e a reflexão-na-ação dos pesquisadores juntamente com a teoria e prática, propondo como atividade um tipo de pesquisa onde se estude os processos em que os participantes adquiram capacidade de compreensão e aprendizado prático". A partir deste pressuposto, pode-se considerar este como um tipo de atividade apropriada a um ensino prático reflexivo - justamente nestas etapas que o I Encontro sobre Educação Especial e Inclusiva da UFABC se propôs, além de corroborar com o ensino de conceitos teóricos, bem como fortalecer a prática pedagógica e inclusiva, na reflexão e na troca de conhecimentos entre profissionais e graduandos.

Para Schön (2000, p. 228 apud TINE, 2015, p.30), o ensino prático reflexivo consiste no método que se faz mais apropriado, pelo fato de o conhecimento estar atrelado a uma das partes da atividade proposta. Contudo, novos conceitos podem ser construídos e apropriados pela prática reflexiva das ações propostas pela pesquisa, bem como demonstrar que a eficácia dos sentidos e significados dos participantes da ação extensionista proposta no presente trabalho, que aconteceu de maneira eficiente, como percebido pelos saberes adquiridos e compartilhados.

Por meio das conversas reflexivas arroladas no âmbito do I Encontro sobre Educação Especial e Inclusiva da UFABC, foi possível criar condições para fomentar reflexões sobre como melhorar a performance na (re)construção de sentidos e significados entre os participantes do evento para posteriormente, pensar em estratégias adequadas e assertivas no ambiente acadêmico do público-alvo da 
educação especial e inclusiva. O fato de este evento apresentar uma conversa reflexiva mediada por professores debatedores, vem ao encontro do processo reflexivo (SCHON, 2000; TINÉ, 2015), buscando identificar e avaliar como conceitos são construídos numa interação entre os participantes profissionais da área e universitários.

A descrição de conhecer-na-ação e reflexão-na-ação segundo Schön (2000, p. 34 apud TINE, 2015, p.32), vem ao encontro deste trabalho, no sentido de analisar o conhecimento tácito adquirido por meio da reflexão da atuação de profissionais da área da educação especial e inclusiva e das experiências dos graduandos da UFABC, em um contexto sócio-histórico-cultural da educação especial e inclusiva no cenário de 2017.

Espera-se que o evento tenha contribuído com a disseminação de práticas inclusivas no âmbito da educação básica, assim como na educação superior, por meio do envolvimento dos professores da rede municipal e estadual, comunidade interna e externa da universidade. Para estudos futuros que visam o compromisso com a implantação de ações extensionistas, sugere-se a descrição detalhada para a criação de um curso de extensão, visando uma formação permanente de professores de educação especial e inclusiva, além da descrição acerca de uma especialização em uma universidade pública, de modo a discutir sobre os passos burocráticos para a criação desse tipo de curso, assim como refletir sobre a estrutura de um curso que garanta as condições de formação adequadas às realidades educacionais inclusivas brasileiras. Certamente, a proposição do estudo não visou esgotar o debate acerca da educação especial e inclusiva, além de que uma ação extensionista, por meio de um evento, conforme descrito não visa garantir a formação em longo prazo dos profissionais, de modo a modificar suas práticas pedagógicas. A descrição e operacionalização de um evento é fundamental, de modo a otimizar o estabelecimento de diretrizes futuras, além de refletir sobre a importância do debate dessa temática, em âmbito regional. Por essa razão, foram traçados objetivos futuros, que ultrapassam as propostas apresentadas nesse trabalho, prevendo ação extensionista intermediaria (visando um curso de extensão) e de longo prazo (como a criação de uma especialização).

\section{REFERÊNCIAS}

BRASIL. Ministério da Educação. Secretaria de Educação Especial.Política nacional de educação especial na perspectiva da educação inclusiva. 2008. Disponível em: <http://portal.mec.gov.br/seesp/arquivos/pdf/politica.pdf>. Acesso em: 06 fev. 2013.

BRASIL. Dados do censo escolar de 2014. Disponível em: <http://www.brasil.gov. br/educacao/2015/03/dados-do-censo-escolar-indicam-aumento-de-matriculas-de-alunos-com-deficiencia>. Acesso em: 5 mar. 2018. 
GATTI, B. A.; BARRETTO, E. S. de S. Professores do Brasil: impasses e desafios. Brasília, DF: UNESCO, 2009.

MENDES, E. G.; ALMEIDA, M. A.; TOYODA, C. Y. Inclusão escolar pela via da colaboração entre educação especial e educação regular. Educar em Revista, Curitiba, v. 41, n. 1, p. 81-93, 2011.

RODRIGUES, I. B.; MOREIRA, L. E. V.; LERNER, R. Análise institucional do discurso de professores de alunos diagnosticados como autistas em inclusão escolar. Psicol. Teor. Prat., São Paulo, v. 14, n. 1, p. 70-83, abr. 2012.

SCHÖN, Donald. A. Educando o profissional reflexivo: um novo design para o ensino e a aprendizagem. Porto Alegre: Artes Médicas Sul, 2000.

SILVEIRA, F. F.; NEVES, M. M. B. J. Inclusão escolar de crianças com deficiência múltipla: concepção de pais e professores. Psicologia: Teoria e Pesquisa, Brasília, v. 22, n. 1, p. 79-88, 2006.

TINÉ, RogérioTimóteo. A (re)construção de sentidos-e-significados de conceitos em uma interação entre surdos e pesquisador ouvinte bilíngue. Dissertação (Mestrado em Linguística) - Programa de Estudos Pós-Graduados em Linguística Aplicada e Estudos da Linguagem. Pontifícia Universdade Católica de São Paulo. São Paulo, 2015.

UFABC. Resolução do CEU Nº 005, DE 11 DE JULHO DE 2016, que define as atividades de Extensão Universitária da UFABC. 2016. Disponível em: <http:// proec.ufabc.edu.br/images/a-proex/portarias-e-resolucoes/resolucoes-2016/ Resolu\%C3\%A7\%C3\%A3o_CEU_005-2016_v_final.pdf>. Acesso em: 5 mar. 2018.

Data de recebimento: 05 de março de 2018.

Data de aceite para publicação: 13 de abril de 2018. 